\title{
Dificuldades na Trajetória Universitária e Rede de Apoio de Calouros e Formandos
}

\author{
Clarissa Tochetto de Oliveira \\ Ana Cristina Garcia Dias \\ Universidade Federal de Santa Maria \\ Santa Maria, RS, Brasil
}

\begin{abstract}
RESUMO
A entrada na universidade envolve mudanças em relação ao ensino médio que demandam adaptação dos estudantes. Essas mudanças podem constituir dificuldades para os alunos, que, frequentemente, buscam auxílio na sua rede de apoio para lidar com as mesmas. Buscou-se conhecer e comparar as percepções de calouros e formandos sobre as principais dificuldades encontradas durante o Ensino Superior e a quem recorrem quando se deparam com essas situações. Foram realizadas entrevistas semiestruturadas com 24 discentes de uma universidade do Rio Grande do Sul. As informações coletadas foram submetidas à análise de conteúdo temática. Identificaram-se três categorias: (1) dificuldades durante a graduação, (2) rede de apoio e (3) mudanças nas relações com os familiares. Foram observadas semelhanças e diferenças entre calouros e formandos quanto aos aspectos investigados. As semelhanças parecem decorrer das demandas características da trajetória universitária e as diferenças podem estar associadas às transformações vividas pelos alunos durante a vida universitária.
\end{abstract}

Palavras-chave: Estudantes universitários; adaptação acadêmica; rede de apoio; pais.

\section{ABSTRACT}

\section{Difficulties During College and Support Network of Freshman and Senior Students}

Getting into the university involves changes from high school that require students' adjustment. These changes may become challenges for the students, who frequently seek help from their support network to cope with them. This study aimed to investigate and compare perceptions of freshman and senior students regarding the main difficulties during college as well as the support network they build. Twenty four college students of Economy and Psychology from a university in Rio Grande do Sul were interviewed. The data collected were examined by content analysis. Three categories were identified: i) difficulties during college, ii) support network, and iii) changes in family relations. Similarities and differences were observed between freshman and senior students concerning the aspects that were investigated. The similarities are likely to be a result of the demands during college and the differences may be associated with changes these students experienced in this period.

Keywords: College students; adjustment to college; support network; parents.

\section{RESUMEN}

\section{Dificultades en la Trayectoria Universitaria y Red de Apoyo de Novatos e Inminentes Graduados}

El ingreso a la universidad implica cambios respecto a la enseñanza media, demandando adaptación de los estudiantes. Ello puede generar dificultades para los alumnos, que generalmente buscan auxilio en su red de apoyo. Se buscó conocer y comparar las percepciones de los novatos y de los inminentes graduados sobre las principales dificultades encontradas en la graduación y a quienes buscaban en esas situaciones. Se realizaron entrevistas semiestructuradas con 24 dicentes de una universidad de Río Grande del Sur. Las informaciones recolectadas fueron sometidas a análisis de contenido temático, identificándose tres categorías: (1) dificultades durante la graduación; (2) red de apoyo; y (3) cambios en la relación con los familiares. Se observaron semejanzas y diferencias entre novatos e inminentes graduados respecto a los aspectos investigados. Aquellas parecen advenir de las demandas características de la trayectoria universitaria, y éstas pueden asociarse a las transformaciones vividas por los alumnos durante la vida universitaria.

Palabras-clave: Estudiantes universitarios; adaptación académica; red de apoyo; padres. 
A trajetória universitária não é caracterizada exclusivamente pela formação profissional. Os estudantes que ingressam no ensino superior são inseridos em uma nova realidade, na qual se deparam com desafios para os quais podem ainda não estar preparados, tais como relacionar-se com pessoas diferentes, ajustar-se a novas regras, assumir novas responsabilidades e lidar com tarefas acadêmicas mais exigentes (Beck, Taylor, \& Robbins, 2003; Soares, Guisande, \& Almeida, 2007; Teixeira, Dias, Wottrich, \& Oliveira, 2008). Assim, o ambiente universitário diferencia-se daquele vivido no ensino médio em diversos aspectos, sendo exigidas diferentes mudanças que demandam adaptações dos indivíduos (Teixeira et al., 2008).

A adaptação acadêmica depende de uma série de fatores que faz com que eles se sintam integrados ao curso e à universidade. Entretanto, esses aspectos nem sempre estão relacionados diretamente ao contexto acadêmico. $\mathrm{O}$ ajustamento ao ensino superior envolve desde o sentimento de pertencer à turma e o conhecimento sobre as oportunidades oferecidas pela universidade até a própria rede de apoio, a qual o calouro pode recorrer em casos de dificuldade (Teixeira et al., 2008). Além disso, não é raro que a entrada na universidade coincida com a separação da família (Beck, Taylor, \& Robbins, 2003; Soares et al., 2007). A saudade de casa (homesickness) tem sido identificada como uma consequência negativa da necessidade de se adaptar a um novo contexto, neste caso, sair da casa dos pais para morar sozinho ou com outras pessoas (Scopelliti \& Tiberio, 2010). Estudantes que vivem sem a família podem apresentar níveis mais elevados de estresse do que estudantes que moram com os familiares (Rull et al., 2011), sendo mais comum encontrar entre os últimos índices mais elevados de adaptação acadêmica (Soares et al., 2007). $\mathrm{O}$ estresse acadêmico refere-se a uma reação adaptativa às demandas do meio que, quando prolongada, pode resultar em uma série de problemas, como desempenho acadêmico pobre, fracasso escolar, entre outros (Rull et al., 2011).

Assim, o ingresso no ensino superior pode se tornar uma experiência estressora para os alunos. Os estudantes tendem a experimentar níveis mais elevados de estresse no início do ano devido aos desafios acadêmicos e sociais apresentados pelo novo contexto (Friedlander, Reid, Shupak, \& Cribbie, 2007). Os calouros podem encontrar diversas dificuldades ao longo da graduação, tais como problemas no desempenho acadêmico, com professores e pares, na gestão do tempo (Liporace, González, Ongarato, Saavedra, \& Iglesia, 2009), na administração dos recursos financeiros, em experiências de trabalho, na capacidade de lidar com a ausência de afeto e aprovação constante dos companheiros, entre outros (Soares et al., 2007). Essas dificuldades podem contribuir para a desadaptação dos jovens ao contexto acadêmico, para insucessos (Páramo et al., 2010) e, até mesmo, para o abandono dos estudos (Rull et al., 2011).

Não é raro que os estudantes busquem neutralizar os efeitos desagradáveis do estresse acadêmico recorrendo a drogas legais e ilegais (Rull, et al., 2011). Nesse sentido, faz-se necessário proporcionar opções aos alunos para lidar com o estresse desse período (Rull, et al., 2011). Uma alternativa consiste na oferta de apoio social, considerado aspecto fundamental para o êxito da adaptação acadêmica (DeAndrea, Ellison, LaRose, SteinField, \& Fiore, 2012) e fator protetor da transição do estudante para a universidade (Friedlander et al., 2007).

Portanto, faz-se necessário ampliar o conhecimento sobre as dificuldades percebidas pelos estudantes durante a graduação (Teixeira et al., 2008), bem como sobre as características da rede de apoio a que os discentes recorrem em situações problema (Lidy $\&$ Kahn, 2006). Nesse sentido, buscou-se conhecer e comparar as percepções de estudantes universitários de início e final de curso de graduação sobre as principais dificuldades encontradas durante o ensino superior e a quem recorrem nessas situações. Pretendeu-se, também, analisar se e como o ingresso na universidade interferiu na relação dos discentes com seus familiares.

\section{MÉTODO}

Participaram deste estudo 24 estudantes universitários (17 mulheres e 7 homens) dos cursos de Psicologia e Economia de uma universidade pública do interior do Rio Grande do Sul. Os alunos estavam cursando o primeiro (11 participantes) ou o último ano da graduação (13 participantes). A idade dos acadêmicos variou entre 17 e 26 anos. Serão utilizados nomes fictícios para se referir aos participantes para preservar o anonimato de suas identidades.

Foi utilizada uma entrevista semiestruturada individual que abordava questões sobre a adaptação dos estudantes à universidade, como dificuldades encontradas e rede de apoio. O contato inicial foi realizado com os coordenadores e professores dos cursos de Economia e Psicologia, solicitando autorização para o desenvolvimento do projeto junto aos alunos. A divulgação sobre os objetivos e os procedimentos do estudo foi realizada de maneira coletiva, em sala de aula, convidando os jovens para participar. Destaca-se 
que a pesquisa foi submetida e aprovada pelo comitê de ética da universidade onde o estudo foi realizado (Protocolo número 23081.09595/2008-77).

As entrevistas foram transcritas e submetidas à análise de conteúdo temática (Bardin, 1979). Realizouse análise de conteúdo dedutiva, uma vez que a estrutura de análise foi baseada em conhecimentos prévios e que se pretendia comparar categorias em períodos de tempo distintos (Castro, Abs, \& Sarriera, 2011). Em um primeiro momento, foram identificadas as respostas que se referiam às dificuldades encontradas na trajetória universitária, bem como à rede de apoio dos estudantes. Após, realizou-se uma leitura exaustiva dos trechos selecionados, que foram agrupados conforme convergência dos conteúdos para dar origem às categorias. Foram definidas três categorias: (1) dificuldades durante a graduação, (2) rede de apoio e (3) mudanças nas relações com os familiares. A primeira categoria apresenta as principais dificuldades encontradas pelos discentes ao longo de sua trajetória universitária. A segunda, denominada rede de apoio, refere-se a quem os estudantes universitários recorrem para lidar com as situações problema e de que forma o auxílio é prestado. A terceira categoria corresponde às mudanças percebidas pelos acadêmicos na sua relação com os familiares, especialmente com os genitores. Por fim, buscou-se verificar se havia semelhanças e diferenças entre os relatos de calouros e formandos no que se refere aos aspectos investigados.

\section{RESULTADOS E DISCUSSÃO}

Os discentes entrevistados neste estudo refletiram sobre sua trajetória universitária até o momento e apontaram as principais dificuldades encontradas durante o Ensino Superior, bem como a quem recorriam em busca de auxílio para lidar com os mesmos. Os acadêmicos também avaliaram a relação que possuem com seus familiares e identificaram mudanças que ocorreram no período em que estavam frequentando o curso de graduação. Essas informações serão apresentadas e discutidas a seguir, com destaque para as semelhanças e diferenças nas percepções de calouros e formandos.

\section{Dificuldades durante a graduação}

Verificaram-se semelhanças em algumas dificuldades enfrentadas por calouros e formandos durante o curso universitário. Os acadêmicos que estavam iniciando e concluindo a graduação relataram encontrar problemas em relação ao curso escolhido, as dificuldades individuais e à saída de casa para aqueles que mudaram de cidade.
No que se refere ao curso escolhido, os calouros de Economia e Psicologia enfrentaram dificuldades referentes ao grau de exigência e didática dos professores e à falta de compreensão dos aspectos burocráticos da formação. Já os formandos lembram da frustração de suas expectativas quando ingressaram na universidade e consideram a falta de opções extracurriculares para aprofundar os estudos como um dos fatores problemáticos encontrado em seu processo de adaptação e formação.

"Dificuldades em relação à texto, ao método de ensino bem diferente. Dai eu tentava buscar ler mais, lia cinco vezes um texto para tentar entender." (Lauro, Psicologia, calouro)

“Tem colegas que já estavam na universidade, então projeto, DCG, ACG, já sabiam dessas coisas. Eu me sentia mal, porque eu era a única que não sabia." (Janaina, Psicologia, caloura)

"Eu imaginava de uma maneira diferente o curso de Psicologia. Eu esperava pessoas mais preocupadas, mais humanas [...] em termos de relações. Isso me dificultou um pouco, senti meio que uma barreira das pessoas cuidando com o que vão falar, essa coisa de psicólogo está sempre analisando." (Nádia, Psicologia, formanda)

"A falta de linhas de pesquisa, de grupos de estudo no curso que tu possa aprofundar discussões." (Denise, Economia, formanda)

O ajustamento à realidade da instituição, que envolve a assimilação das regras de funcionamento, destacase como uma das mudanças que exigem a adaptação dos calouros (Teixeira et al., 2008). Dificuldades no relacionamento com os professores e na adaptação ao curso podem indicar diferenças encontradas entre os ensinos superior e médio (Oliveira, Wiles, Fiorin, \& Dias, no prelo; Ferreira, Almeida, Soares, 2001). Nesse sentido, parece que a ausência de uma orientação sobre os processos burocráticos da instituição podem dificultar a ambientação do calouro à universidade (Teixeira et al., 2008).

Os participantes deste estudo identificaram também dificuldades individuais. A comunicação parece comprometer a apresentação de trabalhos e a interação com outras pessoas, apresentando consequências na integração com os colegas e veteranos. A transição da adolescência para a vida adulta também foi citada como um fator que, somado às necessidades decorrentes dos 
processos de adaptação à universidade, pode interferir na trajetória universitária.

"Se enturmar com os veteranos, eu sentia desconforto porque parecia que já tinha formado, eu me sentia sozinha nos primeiros dias." (Janaina, Psicologia, caloura)

"Eu acho que essa primeira adaptação, que a gente vem com questões da própria adolescência, eu acho que foi um pouco dificil." (Helena, Psicologia, formanda)

De fato, as dificuldades típicas do contexto universitário não se resumem às novas exigências acadêmicas e ao novo ambiente. Questões individuais dos alunos também podem influenciar no desempenho e na própria adaptação acadêmica dos mesmos (Cunha \& Carrilho, 2005; Lidy \& Kahn, 2006). Assim, determinadas características pessoais dos discentes, como timidez, podem despertar sentimentos de solidão nos jovens quando estes ingressam na universidade (Mounts, Valentiner, Anderson, \& Boswell, 2006). A estratégia utilizada pelos discentes para lidar com as emoções, por sua vez, está associada com os níveis de ajustamento à universidade (Johnson, Gans, Kerr, \& LaValle, 2010). Em uma pesquisa realizada nos Estados Unidos, constatou-se que os calouros que evitavam as emoções relatavam mais dificuldades nos processos de adaptação acadêmica do que os alunos que conseguiam lidar com as mesmas. Esses resultados sugerem que a habilidade para administrar as emoções pode proteger os indivíduos de um ajustamento deficitário (Johnson et al., 2010).

Por outro lado, características como estabilidade emocional, extroversão e praticidade estão associadas às percepções de maior apoio social (disponibilidade dos professores e colegas para auxiliar nas dificuldades) e, consequentemente, ao melhor ajustamento à universidade no início da graduação (Lidy \& Kahn, 2006). Além disso, alunos que possuem uma visão melhor de si podem utilizar estratégias mais eficazes para lidar com as demandas acadêmicas e sociais do contexto universitário. Por exemplo, sentimentos de autoeficácia podem gerar confiança nos estudantes para manejar estressores, resultando em melhor adaptação acadêmica dos mesmos (Friedlander et al., 2007).

A saída de casa foi compreendida como uma dificuldade, pelo menos inicialmente, pela maioria dos participantes do estudo que passaram por essa experiência. Os acadêmicos apontam que a saudade dos familiares, o afastamento dos pais, a responsabilidade pelas atividades domésticas e a liberdade são aspectos que podem interferir no seu bem-estar ou atrapalhar a rotina acadêmica. Contudo, alguns discentes reconhecem que a saída de casa lhes proporcionou diferentes aprendizados.

"Uma coisa que eu senti bastante foi ficar longe da familia. No começo, foi dificil, eu fiquei bem perdida, tu tem que te virar com tudo. Chorei um mês, todos os dias eu ligava pra minha mãe, mas eu decidi vir pra cá." (Renata, Economia, caloura)

"É interessante perceber que a gente tem uma liberdade extrema e ao mesmo tempo se dá conta que tem que tomar determinados cuidados, porque se se apertar, não tem quem chamar. Em alguns momentos, eu me dei conta disso e me assustei um pouco. Não tem nem pra quem reclamar nas primeiras semanas. Isso de ter que cuidar da casa, saber que eu ia ter que dar conta sozinho porque não tinha pra quem apelar é interessante e eu compõe um pouco do que é ser adulto." (Carlos, Psicologia, formando)

"Eu tinha que me virar sozinha, chegar em casa, fazer almoço, de tuas roupas acumular e tu só ter tempo pra lavar final de semana. E aqui é assim: ou tu faz, ou não vai ser feito." (Carla, Psicologia, formanda)

Outros participantes do estudo discordam que a saída de casa tenha sido difícil. Estes acadêmicos negam ter enfrentado problemas com essa mudança, apesar de sentirem saudade da família e da necessidade de se adaptar a uma cidade diferente. Além disso, parece que estar preparado para se afastar dos genitores e para dar conta das tarefas domésticas pode contribuir para que os jovens se sintam mais seguros quando forem morar longe dos pais. Assim, é possível que os discentes com maior autonomia ou acostumados a ajudar em casa enfrentem com maior facilidade a saída da casa dos mais.

"Eu sempre soube, quando acabasse o Ensino Médio, eu iria estudar fora. Eu já estava preparado nesse sentido, eu nunca fui aquelas pessoas que os pais fizeram tudo, sempre me ensinaram como se limpa uma casa, como se faz comida." (Márcio, Economia, calouro)

A saída da casa dos pais parece ser um evento marcante para aqueles que decidem estudar em outra cidade. Os relatos dos participantes deste estudo vão ao encontro dos resultados de outra pesquisa com o mesmo 
público, estudantes universitários do sul do Brasil. Os alunos tendem a perceber a experiência de sair de casa como algo difícil, devido aos sentimentos de solidão, ou como algo importante, em virtude da independência conquistada (Teixeira et al., 2008). Os discentes que saem da casa dos pais podem apresentar maiores níveis de autonomia e, ao mesmo tempo, manifestar maiores dificuldades no processo de adaptação à universidade, em decorrência das exigências que se apresentam. Assim, a condição de residência dos discentes durante a graduação, ou seja, morar ou não na casa dos pais, pode afetar a transição e a qualidade da adaptação dos mesmos ao novo ambiente educacional (Soares, 2003).

Outra variável que tem sido investigada como uma consequência negativa da saída dos jovens da casa dos pais quando ingressam na universidade é a saudade de casa (homesickness). Este é um estado de estresse experimentado após a saída da casa dos pais em que o indivíduo sente saudade da família, possui o desejo de voltar para casa, experimenta sentimentos de solidão e pensa bastante sobre a residência anterior (Khademi \& Aghdam, 2013; Nijhof \& Engels, 2007; Scopelliti \& Tiberio, 2010). Uma forma de reduzir a saudade de casa consiste em construir um vínculo positivo com o novo lar, através da substituição de aspectos negativos da residência anterior por aspectos positivos da casa nova. No caso de estudantes universitários, isso ocorre por meio dos sentimentos positivos associados com a nova experiência de moradia e por meio do desenvolvimento pessoal (novas atividades, novas pessoas, lazer e estímulo cultural) que, juntos, levam ao crescimento e independência característicos do início da vida adulta (Scopelliti \& Tiberio, 2010).

Também foi possível identificar dificuldades exclusivas de estudantes calouros ou formandos. Nesse sentido, dúvidas e a falta de apoio familiar em relação à escolha profissional foram apontadas somente por acadêmicos do primeiro ano da graduação. Alguns discentes referiram não ter certeza quanto à decisão pelo curso e que, inicialmente, os genitores não aceitaram a profissão desejada por eles. De acordo com os participantes entrevistados, alguns pais esperavam a decisão por um curso mais prestigiado e outros afirmavam que não ofereceriam suporte financeiro para os estudos.

"A maior dificuldade talvez fosse ter escolhido Psicologia e não Medicina, porque a minha família esperava mais do que Psicologia, mas agora eles aceitaram." (Paula, Psicologia, caloura)

"Eu tive bastante dificuldade com a minha mãe, porque eu não queria fazer Economia, eu queria fazer Matemática. Ela fica dizendo que, se eu fizer Matemática, eu vou ter que pagar minha passagem, meu vestibular, tudo para me virar." (Leandro, Economia, calouro)

Um dos fatores relevantes para a adaptação dos calouros à universidade corresponde ao apoio parental. Supõe-se que o apoio dos pais facilite o processo de identificação do estudante com a profissão, através do estímulo ao envolvimento com o curso, com as atividades propostas e com os professores. Por outro lado, esse incentivo pode não estar presente na trajetória de alunos cuja escolha não corresponde às expectativas parentais (Teixeira, Castro, \& Piccolo, 2007).

A ausência do apoio parental na transição para a universidade pode despertar sentimentos de solidão nos jovens e levar, indiretamente, à ansiedade ou à depressão (Mounts et al., 2006). Nesse sentido, há atividades que podem ser desempenhadas pelos genitores a fim de contribuir para o ajustamento do filho ao ensino superior. Alguns exemplos são mostrarse disponível para participar do desenvolvimento do filho, demonstrar interesse pela vida acadêmica e incentivar os jovens a assumir responsabilidade e confiança na própria trajetória profissional (Pinto \& Soares, 2004). O apoio parental pode levar os discentes a desenvolverem uma percepção de autoeficácia para o trabalho e a satisfação com escolhas profissionais (Bryant, Zvonkovic, \& Reynolds, 2006).

Uma dificuldade que parece característica dos estudantes formandos, por sua vez, corresponde à gestão do tempo. Os discentes referiram dedicar muito tempo aos estudos, o que prejudica outras áreas de suas vidas. Relatam não conseguir conciliar estudos e trabalho, em função das exigências acadêmicas.

"Eu estudava muito, não saía, então chegou um ponto em que eu não estava feliz. Eu estava me dando bem no curso, mas minha vida se resumia ao curso, à convivência com meus colegas e na Casa de Estudante." (Aline, Economia, formanda)

"A maior dificuldade é o fato de trabalhar e estudar, que às vezes não dá tempo de estudar. Às vezes tem matérias que exigem que tu se dedique mais e tu não consegue. Ai tem que sacrificar algum final de semana pra estudar, tem que ficar até mais tarde estudando de noite ou tu pede folga no serviço." (Camila, Economia, formanda)

Uma explicação possível para a gestão do tempo ter aparecido como uma dificuldade específica dos participantes formandos desse estudo é que os 
relacionamentos interpessoais parecem ser mais importantes para o ajustamento dos indivíduos à universidade do que a gestão de responsabilidades nos semestres iniciais. Em outras palavras, a importância do gerenciamento das atividades costuma aumentar nos semestres posteriores (Diniz \& Almeida, 2006). Além disso, a gestão do tempo pode constituir uma das vivências de maior dificuldade na adaptação acadêmica (Cunha \& Carrilho, 2005), já que a necessidade de lidar com uma série de exigências, acadêmicas e administrativas, pode provocar sentimentos de estar perdido e pouca motivação (Teixeira et al., 2008). Assim, questiona-se se dificuldades nessa habilidade podem interferir nas crenças de autoeficácia dos estudantes, uma vez que a falha na administração do tempo pode comprometer as responsabilidades assumidas pelos acadêmicos.

Por fim, não foram observadas dificuldades de adaptação à universidade que implicassem em um fracasso frente às exigências acadêmicas. Da mesma forma que na pesquisa conduzida por Teixeira et al. (2008), os participantes deste estudo não descreveram as dificuldades como aspectos com os quais não conseguissem lidar. Parecem existir dificuldades que permanecem ao longo curso universitário e outras que são características do período em que o discente se encontra, como o início ou o final da graduação. Em outras palavras, é possível que os desafios encontrados pelos alunos mudem conforme o momento que estão vivendo de seus cursos. Assim, o ingresso no Ensino Superior pode ser acompanhado de dúvidas em relação à escolha profissional e da necessidade de adaptação à universidade, às novas responsabilidades e à saída de casa. Já durante a trajetória universitária, é possível que os jovens identifiquem aspectos individuais que precisam ser desenvolvidos e percebam a importância de encontrar formas de conciliar as atividades acadêmicas com a vida pessoal. A partir disso, constata-se o quanto uma rede de apoio pode ser útil para os estudantes, formada por pessoas com quem possam contar nos momentos de maior dificuldade.

\section{Rede de apoio}

As redes de apoio parecem ser fundamentais para o êxito na transição e para a adaptação dos alunos à universidade. A rede de apoio dos estudantes entrevistados era composta, principalmente, por familiares e amigos. Tanto os calouros quanto os formandos relataram que essas pessoas mostram-se presentes durante a sua trajetória universitária e os auxiliam de formas diferentes na adaptação acadêmica.

Os jovens afirmam que a família, especialmente os genitores, oferece apoio emocional para lidar com o ingresso no Ensino Superior, com as dificuldades encontradas no curso escolhido e com a saída de casa. Os discentes relatam ainda que os pais se interessam por sua rotina, estimulam comportamentos exploratórios, conversam sobre os planos futuros e emprestavam materiais quando eram da mesma área de formação. Além disso, os genitores proporcionam suporte financeiro para que os acadêmicos possam estudar e morar em outra cidade quando necessário.

"Em todos os sentidos: psicologicamente, financeiramente. Não falta apoio" (Bruna, Economia, caloura). "Com a minha mãe sobre a dificuldade quando eu me formar, [...] me faz procurar coisas pra que, depois que eu saia, eu tenha pra onde ir." (Betânia, Psicologia, caloura)

"Mais minha mãe, ela conversava comigo. Quando eu preciso, eu também pego material." (Daniela, Psicologia, caloura)

"Me perguntando o tempo inteiro o que eu estou fazendo de projetos. Teve um grande reconhecimento da minha família quando eu consegui uma bolsa [...]. Está se abrindo uma possibilidade pra mestrado e eles estão empolgados que eu vá tentar. Estão preocupados com a qualidade da minha formação profissional, que eu faça o que eu goste." (Angélica, Psicologia, formanda)

"Em relação a dar apoio, a estarjunto, confiando na pessoa, a minha família sempre foi muito presente. [...] O meи pai [...] sempre nos incentivou a estudar, a buscar uma qualificação, desde quando a gente era pequena, ele conversava sobre o mercado de trabalho... Eu acho que eu tenho muito isso dele, essa visão realista de pensar estrategicamente e de pensar que tem algumas coisas que não adianta tu ficar chorando, tu tem que erguer a cabeça pra enfrentar." (Helena, Psicologia, formanda)

Os estudantes entrevistados parecem apreciar o apoio recebido pelos genitores. A oferta de condições para o estudo, de orientações sobre o mercado de trabalho e de suporte emocional parecem constituir fatores facilitadores para a adaptação e permanência na universidade. No entanto, o apoio parental também pode contribuir de forma indireta para o ajustamento ao ensino superior. A base emocional segura oferecida pelos familiares pode contribuir para o sentimento de segurança e de competência social, de forma que os jovens se sintam capazes de enfrentar a ansiedade 
envolvida na separação do ambiente familiar e no estabelecimento de novas relações, refletindo uma maior integração social no contexto universitário (Teixeira et al., 2007).

$\mathrm{O}$ apoio parental direto para a transição para o ensino superior também está associado com a qualidade das amizades estabelecidas. Exemplos familiares de como conhecer pessoas novas auxiliam os estudantes a utilizar as mesmas estratégias de forma efetiva para conhecer pessoas com quem possam se vincular (Mounts et al., 2006).

Por outro lado, houve estudantes que negaram que a família tenha auxiliado na sua adaptação acadêmica. Esses discentes pensam que são os próprios jovens que precisam se ajustar à universidade e não parecem reconhecer o apoio dos familiares como importante para esse processo.

"Eu não sei se chega ajudar na adaptação, porque é tu que tem que te adaptar, não é a tua família." (Aline, Economia, formanda)

Irmãos, primos e tios também parecem desempenhar um papel importante na adaptação acadêmica dos participantes deste estudo. Os discentes afirmam que os irmãos mais velhos contam sobre a própria experiência universitária e alertam os jovens para diferenças dessa experiência quando comparada à escola de Ensino Médio. Ademais, é comum que os estudantes morem com irmãos e primos quando precisam sair da casa dos pais. Nesses casos, tanto os irmãos quanto outros familiares, como tios e avós, auxiliam aos acadêmicos a se adaptar na nova cidade.

"Meus irmãos já passaram pela universidade, eles sempre me falavam como era, que realmente eu ia ter dificuldades, não ia ser aquela coisa do colégio que eu estava acostumada, eu ia ter que correr atrás." (Paula, Psicologia, caloura)

"Eu tenho uma adaptação mais por causa dos meus irmãos. Eu tenho familiares aqui também e o final de semana eu vou almoçar lá." (Lauro, Psicologia, calouro)

Os amigos também parecem auxiliar os estudantes durante a trajetória universitária. Os discentes frequentemente consideram essas pessoas como irmãos ou parte da família, pelo grau de intimidade e pela importância que adquirem ao longo desse período. Esses amigos tendem a ser pessoas que os jovens conhecem no início do curso universitário, colegas ou não, com quem passam a conviver nos momentos extraclasse e que podem ajudar os discentes a lidar melhor com o afastamento da família.

"A casa do estudante, a convivência com o pessoal, [...] são pessoas que eu tenho como irmãos até hoje. [...]. Final de semana a gente passava junto, a gente fazia massa, churrasco. [...] Isso é muito importante quem vem pra cá, saindo de casa, um mundo onde tu não tem amigos, porque a universidade demanda muito estudo, dedicação, mas se a gente entrar só nisso, eu acho que fica muito pesado. [...] No início foi um pouco dificil, eu me sentia sozinha. Por isso que essas pessoas foram importantes, a gente cria um vínculo e consegue lidar melhor com isso." (Letícia, Psicologia, formanda)

A capacidade de criar novas amizades é um componente fundamental para a transição à universidade (Reynolds, 2013), embora o contato com amigos antigos também seja importante (DeAndrea et al., 2012), bem como o contato regular com os pais (Friedlander et al., 2007). A percepção de uma vasta rede de apoio está associada com níveis mais elevados de adaptação acadêmica dos estudantes (Friedlander et al., 2007). Os calouros consideram as amizades estabelecidas nas primeiras experiências universitárias como elementos que podem facilitar seu ajustamento ao ensino superior. Esses vínculos permitem não só o compartilhamento de experiências, expectativas, interesses, problemas e apoio em caso de dificuldades, mas também despertam o sentimento de pertencer a um grupo (Llamas \& Ramos-Sánchez, 2013; London, Rosenthal, Levy, \& Lobel, 2011; Pittman \& Richmond, 2008; Teixeira et al., 2008) e contribuem para o bemestar dos jovens através da criação de uma rede de suporte emocional fora da família (Rosin, 2012).

$\mathrm{O}$ apoio social constitui um elemento imprescindível para a integração dos estudantes à universidade. Contudo, nem sempre os discentes se sentem confortáveis para buscar ajuda, pois se preocupam em não sobrecarregar os outros com seus problemas (Smith, 2014). A partir dessa premissa, uma pesquisa realizada nos Estados Unidos procurou investigar se um site que possibilitasse o contato entre os alunos poderia facilitar a transição do ensino médio para o ensino superior. Constatou-se que o uso deste site pode interferir nas crenças de autoeficácia dos discentes, uma vez que os mesmos percebem sua capacidade de contatar outros estudantes que podem ajudá-los em casos de dificuldade. Além disso, o site contribuiu para a percepção dos alunos sobre a universidade como um lugar onde é possível encontrar os recursos necessários para a resolução dos problemas enfrentados, embora o 
site não incluísse informações sobre hábitos de estudo ou materiais específicos do curso. Assim, parece que facilitar o contato entre calouros pode constituir uma importante fonte de informação, capaz de auxiliar na transição para o ensino superior através da formação de uma extensa rede de apoio (DeAndrea et al., 2012).

Os alunos formandos de Economia e Psicologia que participaram do estudo citaram ainda recorrer aos professores, à internet, a psicólogos e aos estudantes do Diretório Central dos Estudantes (DCE) quando possuíam dúvidas institucionais ou relacionadas à carreira. Questiona-se por que essas opções não foram citadas pelos calouros entrevistados. Pode-se pensar que a ampliação da rede de apoio ocorra ao longo da graduação, quando os discentes estão mais integrados à realidade universitária, participaram de atividades extracurriculares e de estágios. Acredita-se que essas vivências possibilitam o conhecimento de pessoas diferentes, que podem ser identificadas como fontes de suporte alternativas.

"Eu pesquisava na internet, conversava com os professores." (Carolina, Economia, formanda)

"Eu levo pra terapia em relação ao meu lado profissional. [...] Tem uma pessoa no estágio que é psicóloga e eu gosto de conversar com ela em relação a isso, como está sendo a minha experiência." (Helena, Psicologia, formanda)

"Quando era problema institucional, eu catava o pessoal do DCE, me informava, perguntava pro pessoal do sindicato." (Letícia, Psicologia, formanda)

Pode-se pensar que a rede de apoio de estudantes universitários muda ao longo da graduação. Parece que os discentes ampliam as opções a quem podem recorrer para tratar das dificuldades encontradas no Ensino Superior com o passar dos anos. Enquanto os calouros tendem a buscar auxílio com familiares e amigos, os formandos vão além e procuram em outras fontes. Dessa forma, é possível perceber mudanças nas dificuldades e nas relações dos acadêmicos no decorrer da experiência universitária. A partir disso, faz sentido que a relação com os familiares também seja modificada após o ingresso dos jovens na universidade.

\section{Mudança na relação com os familiares}

Em termos gerais, a entrada dos participantes do estudo na universidade modificou a relação dos mesmos com os familiares. Os calouros e os formandos pensam que o ingresso no Ensino Superior, a saída de casa e a transição para a vida adulta contribuíram para o seu crescimento e para a aquisição de maior autonomia. A possibilidade de gerir os estudos sozinho, as novas responsabilidades, a necessidade de tomar as próprias decisões podem ser algumas tarefas da adultez jovem que interferiram nos laços com a família.

"Antes, no colégio, ela (mãe) sabia das minhas nota, que eu não ia na aula [...]. Aqui ela não fica sabendo das coisas, dai eu posso ser mais individual, ela não tem muito motivo pra brigar comigo." (Leandro, Economia, calouro)

"Eu mudei bastante em relação à responsabilidade, algumas opiniões. Eu acho que é por tu estares numa cidade sozinha, sem a tua familia, com as responsabilidades da casa..." (Laura, Economia, caloura)

"Serviu muito pro meu amadurecimento. Eu dou muito valor pras experiências que eu tive aqui no curso. E esse amadurecimento me colocou num lugar diferente em relação aos meus pais. Porque todo mundo dava palpite sobre o que eu ia fazer ou deixar de fazer [...]. Eu noto que eu comecei a conseguir andar pelas minhas pernas." (Nádia, Psicologia, formanda)

"Eu não sei exatamente a entrada na universidade, mas o processo de tornar-se adulto modifica o tipo de relacionamento com eles. Eu trato eles como iguais, não como hierarquicamente superiores. Eu tenho noção de que eu sou financiado por eles, mas eu trato eles com respeito e espero que eles me tratem com respeito, e isso aconteceu depois de ter entrado na universidade." (Hélio, Psicologia, formando)

A autonomia e a responsabilidade ganham importância a partir das mudanças de comportamento e da visão de si mesmo após a entrada no ensino superior. Os calouros compreendem a necessidade de se dedicar ao futuro profissional e de ser mais independente dos familiares, o que implica em assumir tarefas e lidar com as consequências de seus atos. Assim, essa responsabilidade parece estar associada à noção de adultez emergente (Dutra-Thomé, 2013; Teixeira et al., 2008).

Nesta fase, o estudante vivencia uma série de desafios provenientes das tarefas psicológicas normativas da transição da adolescência para a vida adulta que, em conjunto com as exigências da vida universitária, constitui um desafio a ser vencido 
(Cunha \& Carrilho, 2005). No Brasil, os jovens tendem a considerar a aceitação de responsabilidades, a independência financeira e a conclusão dos estudos como critérios importantes para se tornar adulto (DutraThomé, 2013). Dessa forma, a entrada na universidade tem sido considerada uma tarefa de desenvolvimento típica da transição para a vida adulta, especialmente nas camadas sociais mais favorecidas (Teixeira et al., 2008).

Para os alunos entrevistados, os conhecimentos adquiridos no curso de graduação também modificaram a relação com os familiares. Os calouros e os formandos acreditam que a forma como os genitores os vêem mudou agora que os jovens detêm informações específicas de sua área de estudo, diferente daquelas que os pais possuem. Ademais, os discentes sentem-se mais ouvidos e, até mesmo, temidos pela possibilidade de avaliarem as decisões e ações dos genitores.

"Eles começam a te olhar de outra forma, depositam um papel mais importante no curso de Psicologia, está amadurecendo, tu estás aprendendo alguma coisa. Antes eles me viam um estudante normal, mas parece que na Psicologia, eles estão vendo algo que mexe com eles. Eu acho que eles têm medo por achar que eu posso ver que eles falharam em algum momento, na educação..." (Lauro, Psicologia, calouro)

"Dentro da universidade, tu acaba aprendendo um monte de coisa e tu vai levando isso pra casa [...]. Eu acho que eles me ouvem bastante." (Aline, Economia, formanda)

Alguns participantes não perceberam mudança no seu relacionamento com a família. Esses estudantes pensam que eles próprios não mudaram e, por isso, os laços com os genitores também continuam iguais. Além disso, acreditam que a transformação maior ocorre com aqueles que precisam sair de casa e morar em outra cidade para estudar. De fato, os discentes que saíram de casa afirmaram que a relação com os pais ficou mais forte em função do afastamento dos mesmos.

"Eu continuei na cidade, tendo os mesmos hábitos que eu tinha, a mesma relação com eles, então não mudou nada. Eu acho que é mais pra quem muda de cidade e deixa os pais lá." (Fabiana, Economia, formanda)

"A relação pai-filho, mãe-filho ficou até mais forte pelo afastamento, dai tu tem que ter um laço maior." (Leonardo, Economia, calouro)
Os estudantes do último ano da graduação de Economia e Psicologia identificaram seu afastamento da família em decorrência da rotina acadêmica. O envolvimento desses alunos com os estudos parece ter diminuído o tempo dedicado aos familiares. Então, eles contam com a compreensão dos genitores a respeito dessas ausências necessárias e tentam gerir o tempo para que possam dar atenção aos pais, sem prejudicar o desempenho acadêmico.

"Na medida que a gente amadurece, que a gente se afasta de casa, que não é aquela coisa de colégio. Muitas vezes, tem que sair pra ir na faculdade, ficar até tarde pra alguma aula, pra algum trabalho. Então acho que amadureceu bastante a relação." (Camila, Economia, formanda)

"É inevitável que ocorra um afastamento no que diz respeito à convivência diária, mas não houve uma quebra. Sempre fui muito pra casa e me organizava pra no final de semana ir embora, mesmo que eu tivesse que estudar lá." (Carlos, Psicologia, formando)

A preocupação em equilibrar o tempo dedicado à família e aos estudos foi mencionada somente pelos formandos entrevistados neste estudo, o que pode ser compreendido a partir do estresse gerado pelas mudanças e pela carga de trabalho desse período (Beck et al., 2003). No entanto, questiona-se o motivo dessa preocupação ser específica dos formandos, uma vez que são os calouros que, teoricamente, estão mais expostos à necessidade de lidar com as diversas responsabilidades características do ingresso na universidade. É possível que os calouros não tenham clareza do processo de administração do tempo entre universidade e família por estarem em processo de adaptação à saída de casa. Além disso, os calouros podem não ter se sentido preparados para falar nesse tópico no decorrer da entrevista devido à ansiedade e insegurança geradas pela saída de casa. Assim, é provável que tenham essa vivência mais clara ao final do curso.

Por outro lado, os estudantes concluintes estão envolvidos com tantas tarefas quanto os jovens ingressantes, com a diferença de essas atividades estarem relacionadas com estágios e relatórios de final de graduação, bem como com os planos futuros. Nesse sentido, chama atenção que os formandos não tenham mencionado preocupações com a decisão de carreira nem com a inserção no mercado de trabalho. Uma possível explicação para isso é o fato de esses jovens já estarem, de alguma forma, inseridos no mercado 
de trabalho, uma vez que alguns já estão realizando estágio e/ou trabalhando.

Percebe-se que a relação dos estudantes universitários com seus familiares foi modificada após o ingresso no Ensino Superior. O crescimento, a maior autonomia e os conhecimentos adquiridos na graduação foram percebidos pelos discentes de início e fim de curso como fatores capazes de provocar mudanças em si e, consequentemente, nos laços que possuem com os genitores. $\mathrm{O}$ afastamento entre os jovens e seus pais provocado pelas atividades acadêmicas foi percebido somente pelos formandos entrevistados. De forma geral, todos esses aspectos foram atribuídos não só à entrada na universidade, mas também à saída de casa $\mathrm{e}$ à transição para a vida adulta.

Essas informações podem ser interpretadas com base no conceito de adultez emergente. Esta se refere a um período de transição entre adolescência e adultez com características próprias (idade da exploração da identidade, da instabilidade, da autonomia, de não ser adolescente nem adulto, e das possibilidades) e tem sido investigada em diferentes países (Arnett, 2011; DutraThomé, 2013; Nelson, 2009; Seiter \& Nelson, 2011). O presente estudo mostra a autonomia e o afastamento da família como indicadores da transição para a vida adulta. De fato, jovens brasileiros tendem a considerar a aceitação de responsabilidades e a conclusão dos estudos como critérios importantes para se tornar adulto (Dutra-Thomé, 2013). Da mesma forma, jovens romenos e indianos valorizam a responsabilidade pelas próprias ações como critério fundamental para se tornar adulto, embora considerem, também, outros fatores, como evitação de drogas ilegais e independência na tomada de decisões (Nelson, 2009) e a capacidade de oferecer segurança à família e o controle das emoções (Seiter \& Nelson, 2011).

\section{CONCLUSÕES}

O objetivo deste estudo foi conhecer e comparar as percepções de estudantes universitários de início e final de curso de graduação sobre as principais dificuldades encontradas durante o Ensino Superior e as redes de apoio a que recorrem nessas situações. Também foi analisado se e como o ingresso na universidade interferiu na relação dos discentes com seus familiares. Os relatos dos participantes permitiram constatar que não houve diferenças entre estudantes de Economia e Psicologia, mas que há semelhanças e diferenças entre calouros e formandos no que se refere aos aspectos investigados. As semelhanças parecem decorrer das demandas características da trajetória universitária e as diferenças podem estar associadas às transformações vividas pelos alunos durante este período. Essas informações podem ser úteis para os serviços de apoio ao estudante das universidades. É importante que os profissionais desses setores saibam em que circunstâncias pode ser válido trabalhar com jovens de início e de final de curso de forma integrada e em que situações a separação desses públicos pode trazer mais vantagens no atendimento de suas necessidades.

Esta pesquisa possui algumas limitações que devem ser consideradas na interpretação dos resultados. Foram entrevistados estudantes universitários de apenas dois cursos (Economia e Psicologia) de uma universidade pública do Rio Grande do Sul. É possível que discentes de cursos de outras áreas, como rurais, exatas ou saúde, possuam percepções diferentes sobre as dificuldades encontradas durante a graduação e redes de apoio distintas. Além disso, algumas situações consideradas problemáticas pelos acadêmicos de universidades públicas podem não ocorrer com jovens de instituições particulares. Ressalta-se, ainda, que estes resultados podem também ter sido enviesados por questões de gênero dos estudantes (predominantemente do sexo feminino). A partir disso, sugere-se que mais pesquisas sejam realizadas abrangendo acadêmicos de cursos de outras áreas, no intuito de verificar se as dificuldades, as redes de apoio e a relação com os familiares apresentam elementos e funcionamento diferentes das encontradas neste estudo.

Questiona-se, ainda, se os colegas estão incluídos no grupo de amigos descrito pelos estudantes. Dessa forma, sugere-se que mais estudos sejam realizados abordando como é a relação dos discentes com os colegas e se as expectativas foram satisfeitas. O sentimento de pertencer ao grupo também poderia ser investigado, buscando verificar a influência dessa integração no desempenho acadêmico dos jovens. Estas informações podem guiar propostas da coordenação e de professores dos cursos que estejam interessados em favorecer a integração dos alunos durante a graduação.

\section{REFERÊNCIAS}

Arnett, J. J. (2011). Emerging adulthood(s): The cultural psychology of a new life stage. In J. A. Lene, (Ed.). Bridging cultural and development approaches to psychology: New synthesis in theory, research and policy (pp. 255-275). Oxford: University Press.

Bardin, L. (1979). Análise de Conteúdo. Lisboa: Edições 70.

Beck, R., Taylor, C., \& Robbins, M. (2003). Missing home: sociotropy and autonomy and their relationship to psychological distress and homesickness in college freshmen. Anxiety, Stress and Coping, 16, 155-162. doi: 10.1080/10615806.2003.10382970

Bryant, B. K., Zvonkovic, A. M., \& Reynolds, P. (2006). Parenting in relation to child and adolescent vocational development. Journal of Vocational Behavior, 69, 149-175. http://dx.doi. org/10.1016/j.jvb.2006.02.004 
Castro, T. G., Abs, D., \& Sarriera, J. C. (2011). Análise de conteúdo em pesquisas de Psicologia. Psicologia: Ciência \& Profissão, 31(4), 814-825. http://dx.doi.org/10.1590/S141498932011000400011

Cunha, S. M., \& Carrilho, D. M. (2005). O processo de adaptação ao ensino superior e o rendimento acadêmico. Psicologia Escolar e Educacional, 9(2), 215-224. http://dx.doi.org/10.1590/S141385572005000200004 .

DeAndrea, D. C., Ellison, N. B., LaRose, R., Steinfield, C., \& Fiore, A. (2012). Serious social media: On the use of social media for improving students' adjustment to college. Internet and Higher Education, 15, 15-23.

Diniz, A. M., \& Almeida, L. S. (2006). Adaptação à universidade em estudantes de primeiro ano: Estudo diacrónico da interacção entre o relacionamento com pares, o bem-estar pessoal e o equilíbrio emocional. Análise Psicológica, 1(XXIV), 29-38

Dutra-Thomé, L. (2013). Emerging adulthood in southern brazilians from differing socioeconomic status: social and subjective markers. (Tese de Doutorado, Universidade Federal do Rio Grande do Sul).

Ferreira, J. A., Almeida, L. S., \& Soares, A. P. C. (2001). Adaptação acadêmica em estudantes de $1^{\circ}$ ano: diferenças de género, situação de estudante e curso. Psico-USF, 6(1), 01-10.

Friedlander, L. J., Reid, G. J., Shupak, N., \& Cribbie, R. (2007). Social support, self-esteem, and stress as predictors of adjustment to university among first-year undergraduates. Journal of College Student Development, 48(3), 259-274.

Johnson, V. J., Gans, S. E., Kerr, S., \& LaValle, W. (2010). Managing the transition to college: family functioning, emotion coping, and adjustment in emerging adulthood. Journal of College Student Development, 51(6), 607-621.

Khademi, A., \& Aghdam, A. A. F. (2013). The role of personality traits and resilience on homesickness of college students. Procedia - Social and Behavioral Sciences, 82(3), 537-541. http://dx.doi.org/10.1016/j.sbspro.2013.06.305

Llamas, J., \& Ramos-Sánchez, L. (2013). Role of peer support on intragroup marginalization for latino undergraduates. Journal of Multicultural Counseling and Development, 41(3), 158-168. doi: 10.1002/j.2161-1912.2013.00034.x

Lidy, K. M., \& Kahn, J. H. (2006). Personality as a predictor of first-semester adjustment to college: the mediational role of perceived social support. Journal of College Counseling, 9, 123-134. doi: 10.1002/j.2161-1882.2006.tb00099.x

Liporace, M. F., González, N. C., Ongarato, P., Saavedra, E., \& Iglesia, G. (2009). Estrategias de afrontamiento frente a problemas académicos en estudiantes medios y universitarios. Revista Iberoamericana de Diagnòstico y Evaluaciòn Psicològica, 27(1), 63-84.

London, B., Rosenthal, L., Levy, S., \& Lobel, M. (2011). The influences of perceived identity compatibility and social support on women in nontraditional fields during the college transition. Basic and Applied Social Psychology, 33, 304-321. doi: 10.1080/01973533.2011.614166

Mounts, N. S., Valentiner, D. P., Anderson, K. L., \& Boswell, M. K. (2006). Shyness, sociability, and parental support for the college transition: relation to adolescents' adjustment. Journal of Youth and Adolescence, 35(1), 71-80. doi: 10.1007/s10964-005-9002-9

Nelson, L. J. (2009). An examination of emerging adulthood in Romanian college students. International Journal of Behavioral Development, 33(5), 402-411. doi: 10.1177/0165025409340093

Nijhof, K. S., \& Engels, R. C. M. E. (2007). Parenting styles, coping strategies, and the expression of homesickness. Journal of Adolescence, 30, 709-720. http://dx.doi.org/10.1016/j. adolescence.2006.11.009

Oliveira, C. T., Wiles, J. M., Fiorin, P. C., \& Dias, A. C. G. (no prelo). Percepções de estudantes universitários sobre a relação professor-aluno. Psicologia Escolar e Educacional.
Páramo, M. F., Rodriguéz, M. S., Tinajero, C., Guisande, M. A., Castelo, A. M., Martinez, Z., \& Almeida, L. S. (2010). Relevancia de los sistemas de soporte social y nivel de integración en el marco de la convergencia al espacio europeo de Educación Superior: una propuesta de investigación en la Universidad de Santiago de Compostela. In Actas do Congresso Ibérico Ensino Superior em Mudança: tensões e possibilidades (p. 441), Braga: Universidade do Minho.

Pinto, H. R., \& Soares, M. C. (2004). Approches de l'influence dês parents sur le développement vocationnel des adolescents. L'orientation scolaire et professionnelle, 33(1), 1-18.

Pittman, L. D., \& Richmond, A. (2008). University belonging, friendship quality, and psychological adjustment during the transition to college. Journal of Experimental Education, 76(4), 343-361. doi: 10.3200/JEXE.76.4.343-362

Reynolds, M. A. (2013). Trapped in transition: Examining firstsemester college students' discursive struggles about home and school. (Tese de Doutorado, University of Kentucky).

Rosin, A. B. (2012). Bem-estar subjetivo, personalidade e vivências acadêmicas em estudantes universitários (Monografia de especialização em psicologia, Universidade Federal do Rio Grande do Sul).

Rull, M. A. P., Sánchez, M. L. S., Cano, E. V., Méndez, M. T. C., Montiel, P. H., \& García, F. V. (2011). Estrés académico en estudiantes universitarios. Psicología y Salud, 21(1), 31-37.

Scopellti, M., \& Tiberio, L. (2010). Homesickness in university students: the role of multiple place attachment. Environment and behavior, 42(3), 335-350. doi: 10.1177/0013916510361872

Seiter, L. N., \& Nelson, L. J. (2011). An examination of emerging adulthood in college students and nonstudents in India. Journal of Adolescent Research, 26(4), 506-536. doi: 10.1177/ 0743558410391262

Smith, M. E. (2014). Connecting students and families for support during the college transition. In Doctoral Consortium, XVII ACM Conference on Computer Supported Cooperative Work \& Social Computing (p. 93). Baltimore, Maryland: Association for Computing Machinery. doi: 10.1145/2556420.2556832

Soares, A. P., Guisande, M. A., \& Almeida, L. S. (2007). Autonomía y ajuste académico: un estudio con estudiantes portugueses de primer año. International Journal of Clinical and Health Psychology, 7(3), 753-765.

Soares, A.P. (2003). Transição e adaptação ao Ensino Superior: Construção e validação de um modelo multidimensional de ajustamento de jovens ao contexto universitário. (Tese de Doutorado, Universidade do Minho).

Teixeira, M. A. P., Castro, G. D., \& Piccolo, L. R. (2007). Adaptação à universidade em estudantes universitários: um estudo correlacional. Interação em Psicologia, 11(2), 211-220.

Teixeira, M. A. P., Dias, A. C. G., Wottrich, S. H., \& Oliveira, A. M. (2008). Adaptação à universidade em jovens calouros. Revista Semestral da Associação Brasileira de Psicologia Escolar e Educacional, 12(1), 185-202.

\section{Autores:}

Clarissa Tochetto de Oliveira -- Psicóloga. Mestranda no Programa de PósGraduação em Psicologia da Universidade Federal de Santa Maria. Bolsista CAPES/DS.

Ana Cristina Garcia Dias - Psicóloga. Mestre em Psicologia pela Universidade Federal do Rio Grande do Sul. Doutora em Psicologia pela Universidade de São Paulo. Professora do Departamento de Psicologia da Universidade Federal de Santa Maria.

Endereço para correspondência:

Clarissa Tochetto de Oliveira

Rua Porto Verde, 185 - Bairro Camobi

CEP 97110-590 Santa Maria, RS, Brasil

Tel.: (55)9953-8015

E-mail: clarissa.tochetto@gmail.com

Recebido em: 09.05.2013

Aceito em: 29.05.2014 